ISSN 0975-3311

Ushus JBMgt, 9, 1 (2010) 71-25

https://doi.org/10.12725/ujbm.16.2

\title{
MANAGING EMPLOYEE ABSENTEEISM
}

\section{Joseph Sebastian Thekedam*}

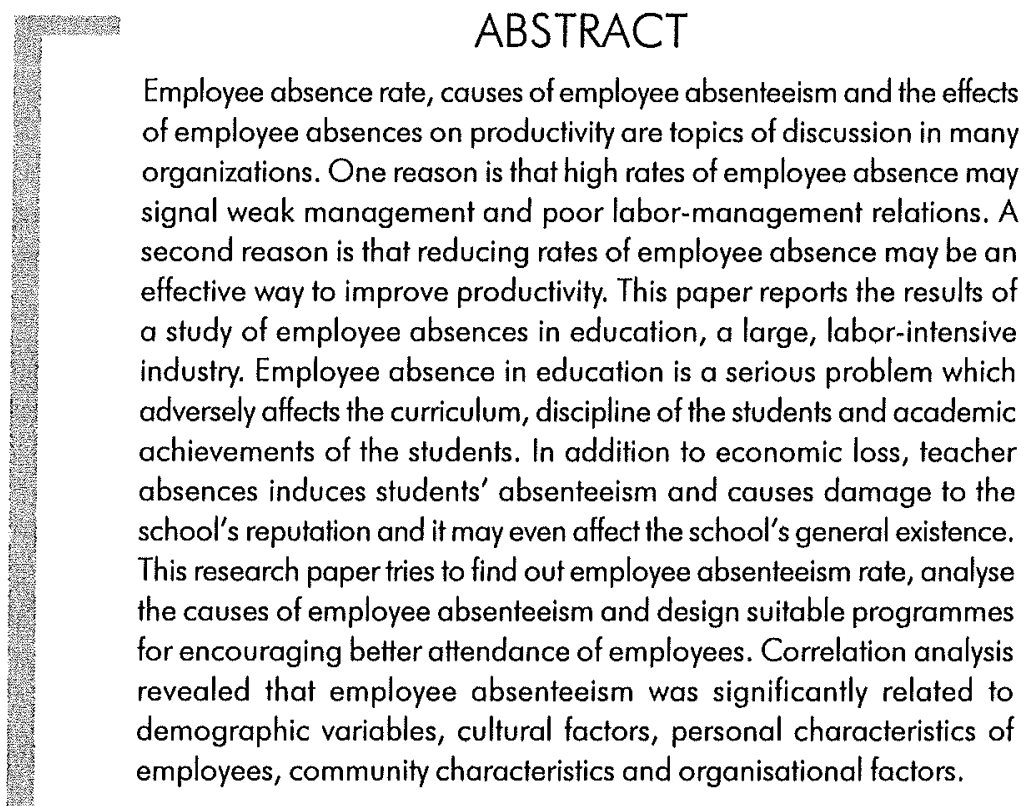

* St. Berchmans' College, Changanacherry, Kerala State. E-mail: jsthekkedam@yahoo.com. 


\section{Introduction}

Employee absenteeism is one of the major management problems faced by most of the organizations, today. Absenteeism has many varied implications on business organizations, in which the main direct and indirect influence is economic. However, the problem of absenteeism is very precarious in schools, in which teacher absenteeism causes additional damage, beyond the economic, and strongly affects the school's general existence - loss of school days that diminish the students' achievements, cause damage to the school's reputation and induce students' absenteeism (Jacobson, 1989, p. 281).

Fundamentally educational practices in Government schools of Kerala have changed little in the past century: it still usually requires a teacher leading a classroom full of students, meaning that the physical presence of both is required. In Government schools of Kerala, where substitute teachers are uncommon, absence of a school teacher may have various consequencesidle time for students, doubling up of classes, and even student dropouts if absence becomes frequent enough.

This research paper probes the extent and correlates of teacher absence in Government schools of Kerala. First, it provides the estimates of teachers' absence rates in Government schools of Kerala. Second, it explores the potential individual, institutional, community and school-level explanatory factors that are most correlated with teacher absence.

\section{Literature Review}

There are a few systematic studies that give insight into the extent of teacher absence, let alone most of its possible determinants. Jacobson, Gibson and Ramming suggest that a set of beliefs and practices among a school's staff concerning what frequency and duration of absence is individually and organizationally acceptable, or what they define as the 'absence culture', can be of critical importance (Jacobson et al., 1993, p. 5). The social context of the school may have more bearing on its absenteeism level than the sum of individuals' contributions to that level. Workplace norms which tolerate high levels of absence are likely to maintain those levels irrespective of who is appointed to the staff. Imants \& van Zoelen emphasise the role of the school's principal in establishing and maintaining those norms (Imants, \& Zoelen 1995, p. 79). Their notion that a school 
manager should express care for teachers' welfare and well-being is consistent with Dworkin, Haney and Teleschov's finding that teachers assigned to schools with a 'supportive' principal experienced less stress-induced illness than others (Dworkin et al., p. 63). Within Imants \& van Zoelen's framework, however, a supportive leader is also a directive one, with little tolerance for those who cause extra work for colleagues (Imants, \& Zoelen 1995, p. 83). It seems a truism that a school where teachers feel happy and appreciated will be less likely to have high levels of staff absenteeism than one where the reverse is the case (Norton 1998, p. 1998).

Cott and McClellan write that the school level taught and the levels of the teaching license were two primary predictors of teacher absences. Through their investigation, it was discovered that the higher the degree obtained by the teacher, the higher the number of days they were absent from the classroom (Scott \& McClellen 1990, p. 231). Based on the research of Unicomb, Alley, and Barak, gender and life stage plays an important part in determining the profiles of teachers who are absent from the instructional environment (Unicomb et al. 1992, p. 34). It was discovered that female teachers tend to be absent more as they increased with age. Male teachers were out more days in their thirties than at any other time in their teaching career. Ponwoll believes that novice teachers with two to four years of experience and veteran teachers who have worked within the educational arena between twenty- three to twenty- five years miss the fewest number of days of school. Novice teachers are still in the infant developmental phase of their career and tend to have fewer personal responsibilities, such as child rearing (Porwoll 1980, p 84). However, Jacobson found that teachers who were nearing retirement were absent on a more frequent basis (Jacobson 1990, p. 81). In a study by Pitkoff, teachers who received low performance markings tend to miss a larger number of days than those who did not (Pitkoff 1993, p. 42).

\section{Theoretical Framework}

The most cited absenteeism model that is used in a multitude of studies on teacher absenteeism was the Steers and Rhodes' model (Steers \& Rhodes 1978, p. 392). They used a multi- variable approach that encompasses psychological as well as personal characteristics of teachers. Based on the ideas of Steer and Rhodes, demographic variables such as personal and family- related characteristics are slated as well as psychological variables such as job satisfaction, motivation to be absent, and the ability to attend 
work. The model emphasizes that attendance is highly influenced by the practices of the organization, school culfure, and employee attitudes, values, and goals. The number one factor identified by Steers and Rhodes was job satisfaction. Other employee attitudes that are related to attendance motivation are job involvement, organisational commitment, loyalty to coworkers and so on. The relationship between attendance motivation and actual employee attendance is constrained by an employee's perceived ability to attend work. This perception is influenced both by organisational practices and by attendance barriers. Attendance barriers include illness, family responsibilities and transportation problems. In this study Steers and Rhodes' model is used to identify factors that might be related to absenteeism in Government schools of Kerala. It is hypothesized that the variables selected would be significantly related to, and contributes substantially to, explaining differences in the absenteeism rates as specified by Steers and Rhodes.

\section{Government Schools in Kerala}

There are 12646 schools in Kerala as per the figures of 2009 (Government of Kerala, Economic Review 2009, p. 262). Out of these 4500 are Government schools, 7284 are Government aided private management schools and 862 are unaided schools. This means Government schools comprise $35.58 \%$ of total schools in the State. There are 999 Government High schools, 953 Government Upper Primary Schools and 2548 Government Lower Primary Schools The number of teachers in Kerala during 2008-09 was 1,74978. Out of this $31.03 \%$ of teachers are working in Government schools. $30.30 \%$ of total students are studying in Government schools.

\section{Objectives of the Study}

The study was conducted to:

- determine teacher absenteeism rate in Government schools of Kerala; and

- find out specific reasons for their absence from schools

- design suitable programmes for encouraging better attendance of teachers. 


\section{Methodology}

\section{Data Collection}

Data for this study were gathered primarily through direct physical observation of attendance, followed by interviews with school headmasters and individual teachers, carried out during unannounced visits to a random sample of 100 Government schools of Kerala. Using the teachers' attendance registers and schedule obtained from the headmasters, the researcher drew up the list of teachers to be observed and interviewed.

Absenteeism data and information about employee characteristics were taken from personnel records. To complement the data collected through questionnaires at the school and individual level, the researcher carried out a parallel effort to gather institutional information and about how these institutions work in practice. Although clearly marked as optional, each respondent was asked to write his or her address on the instrument to allow questionnaire data to be matched with corresponding personnel records. The confidentiality of individual responses was stressed.

\section{Variable Measures}

The questionnaire included the demographic information of gender, age, years of teaching experience, educational qualifications, number and presence of dependents in the household other than spouse and distance from home to work etc. Two absenteeism measures were collected for this study - 1) absence frequency (occurrences) and 2) total days absent which are the most commonly reported measures of absenteeism (Breaugh 1981, p. 556). A portion of Mohrman-Cooke-Mohrman Job Satisfaction Scales was used to measure job satisfaction of the teachers. To measure job involvement, a portion of Michigan Organisational Assessment Questionnaire was included. The Role Conflict Scale assessed the degree of conflict a teacher feels exists between work, spouse, children or community. The respondents were asked to choose on a 6-point continuum from strongly disagree to strongly agree. A "not applicable" response was also offered.

\section{Data Analysis}

Comparisons were made on age, tenure, absence frequency, and the number of days absent. Canonical correlation analysis was used for 
exploring the relationships among multiple dependent variables and the multiple independent variables. This methodology was chosen because the interest in this study concerned the strength of the interrelationships between the sets of multiple dependent and independent variables. In calculating teacher absence rates, we have taken only those permanent teachers who were working full time. The overall teacher absence rate for the two rounds is 10.6 percent. There is substantial variation between the two rounds: 12.5 percent of teachers were absent during the first round of visits, compared with only 8.7 percent in the second round.

Table 1 : Reasons given by school headmasters for the absence of full-time teachers

\begin{tabular}{|l|c|}
\hline & Percentage of those absent \\
\hline Official teaching-related duty & 21.3 \\
Leave for administrative tasks & 4.6 \\
Sick & 9.3 \\
Authorized leave & 14.2 \\
Went to pick up salary & 3.5 \\
Expecled to arrive later & 1.6 \\
Unauthorized absence & 1.4 \\
No reason given & 44.1 \\
Total absent & 100 \\
\hline
\end{tabular}

Table 1 shows that of the teachers who were recorded as absent, only about 23.5 percent were reported to be out of school for reasons that would generate a leave record of some kind-that is, authorized leave and sickness. Another 25.9 percent were reported as being away from the school on some official duty. Thus even if we take the "official duties" and leave reports at face value, we are left with 50.6 percent of the absent teachers who are out of school for other reasons.

\section{Findings}

In table 2, the correlation of teacher absence with certain geographic, individual, school, and institutional variables are given. 
Table 2 : Teacher absence rates by correlates of interest

\begin{tabular}{|c|c|c|c|c|}
\hline & $\begin{array}{l}\text { Mean } \\
\text { absence } \\
\text { rate }(\%)\end{array}$ & & $\begin{array}{c}\text { Mean } \\
\text { absence } \\
\text { rate }(\%)\end{array}$ & Difference \\
\hline Teacher Characteristics & & & & \\
\hline Femole & 11.2 & Male & 7.1 & 4.1 \\
\hline Born this district & 6.0 & Not born in this district & 8.7 & -2.7 \\
\hline Head teacher & 9.0 & Other teacher & 14.0 & -5.0 \\
\hline Requested ossignment to this school & 7.2 & Did not request assignment to this school & 11.4 & -4.2 \\
\hline Post-graduate degree & 14.0 & No post-graduate degree & 9.8 & 4.2 \\
\hline Parent Teacher & 11.1 & Not o parent & 9.5 & 1.6 \\
\hline School Chorocteristics & & & & \\
\hline Distance to poved rood $<15 \mathrm{~km}$ & 9.5 & Dislance to paved road $>15 \mathrm{~km}$ & 21.3 & -11.8 \\
\hline Rural area & 18.7 & Urban area & 9.2 & 9.5 \\
\hline $\begin{array}{l}\text { Infrastructure index (excl. toilet) } \\
<\text { median }\end{array}$ & 11.1 & $\begin{array}{l}\text { Infrostructure index (excl. toilet) } \\
>\text { median }\end{array}$ & 8.5 & 2.6 \\
\hline Discipline index below medion & 11.5 & Discipline index above medion & 11.5 & 0.0 \\
\hline School recently inspected & 8.00 & School not recently inspected & 14.0 & -6.0 \\
\hline School size below medion & 9.1 & School size above medion & 11.1 & 2.0 \\
\hline Recent parent meeting & 8.2 & No recent parent meeting & 12.4 & 4.2 \\
\hline Teacher recognition program & 6.9 & No teacher recognition progrom & 11.3 & 4.4 \\
\hline $\begin{array}{l}\text { Tronsformotional style of leadership } \\
\text { Community Characteristics }\end{array}$ & 4.6 & Laissez-faire style of leadership & 14.9 & 10.3 \\
\hline Maternol \& Paternal literacy below 85\% & 16.4 & Moternal \& Potennal literacy above 85\% & 7.7 & 8.7 \\
\hline Poverty rate below $60 \%$ & 8.7 & Poverty rote above $60 \%$ & 17.8 & -9.1 \\
\hline $\begin{array}{l}\text { Privale School exists nearby } \\
\text { Doy of Observation }\end{array}$ & 7.7 & No private School near by & 16.7 & -9.0 \\
\hline Monday & 15.0 & Other days & 8.0 & 7.0 \\
\hline Tuesday & 8.6 & Other days & 9.7 & -1.1 \\
\hline Wednesday & 9.0 & Other doys & 10.0 & -1.0 \\
\hline Thursday & 10.2 & Other days & 8.9 & 1.3 \\
\hline Friday & 16.8 & Other days & 10.4 & 6.4 \\
\hline First round of survey & 12.1 & Second round of survey & 8.8 & 3.3 \\
\hline
\end{tabular}


If we turn to look at the individual characteristics in Table 2, we see that male teachers $(7.1 \%)$ are less likely to be absent than are female teachers (11.2\%), and non-parent teachers (9.5\%) have slightly lower absence rates than parent teachers (11.1\%), which shows that competing domestic responsibilities are a major cause of absence. This finding is in consistent with the research results found by Scott and McClellan (Scott \& McClellen 1990, p. 230).

The result of this study also shows that the higher the educational degree obtained by the teachers, the higher the number of days they were absent from the classroom. Mean absence rate of post-graduate degree teachers is $14.0 \%$ in comparison to the mean absence rate of non post-graduate degree teachers $(9.8 \%)$. This finding is similar to the results found in the studies of Ponwoll (Porwoll 1980, p. 12).

Table 2 provides evidence for the view that teacher absence is concentrated in poor and more remote areas. Teachers at schools in higher poverty areas are absent twice as often as other teachers. For teachers at remote schools, absence rates are two and a half times higher than those of other teachers. The remoteness of a school predicts higher absence, for two reasons. The first is logistical: transportation difficulties in remote areas may make it harder for a teacher to arrive at school on time. Second, from the perspective of teacher motivation, teachers may find remote posts less attractive. Teachers in these remote locations may spend more time away from their postings, for example heading to urban areas for weekends. The finding on distribution of absences through the week is consistent with this story. If social pressure on teachers and intrinsic orientation toward service to the community are important, then teachers who come from the area near the school might have lower absence rates. In our data, this effect comes through strongly. A teacher who is born in the district where the school is located has a much lower absence rate-typically some 6 percentage points lower-and the effect is generally highly significant.

School size could affect the degree of responsibility the teacher feels to his or her students. Table 2 shows that teachers in larger schools are more likely to be absent (11.1\%) than those in smaller schools (9.1\%): increasing the number of teachers in a school by one standard deviation, for example, would be associated with roughly a 2-percentage-point increase in the probability of absence. One possible interpretation of this result is that some teachers take advantage of the more diffuse responsibility that comes with a larger school. 
Another factor that influences teacher absence is the quality of the school's infrastructure and facilities. Like other employees, teachers are likely to prefer a workplace that has more comforts, as well as better school supplies. Table 2 shows that this measure is also significant, with a one standard deviation increase in the index (about 1.7 points) corresponding to a 2 percentage point decrease in absence.

One possible mechanism for inducing greater teacher effort is frequent unannounced inspections by local education officials. The teacher absence rate of the schools recently inspected is only $8.00 \%$ compared to $14.0 \%$ teacher absence in the schools not recently inspected.

Similarly, implementation of programs to recognize good teachers also improves teacher attendance. The average teacher absence rate is only $6.9 \%$ in schools where teacher recognition program were conducted as compared to $11.3 \%$ teacher absence rate in schools where no teacher recognition program were conducted. This finding is in consistent with the research results found by Scott, Markham, and Robers (Scott et al. 1985, p. 8).

Attendance of teachers also depends on the management style of the school head teacher, including his or her willingness to use disciplinary measures when necessary. Collegial relations and leadership style of the head teacher are found to be associated with the rate of teacher absences. Teachers who have supportive principals are less absent (4.6\%) than those with unsupportive principals (14.9\%). This finding is similar to the results found in the studies of Dworkin, Haney, Dworkin, and Telschov (Dworkin et al. 1990, p. 64).

The study regarding the positive role that community involvement can play in school management suggests that giving greater discretion to parents and communities can reduce teacher absence. The most obvious vehicle for parental involvement in the management of schools is the parents' association. Mean absence rate of teachers in schools where there were sufficient community involvement and recent parent meetings was $8.2 \%$ where as the mean absence rate of teachers in schools where there were inadequate community involvement and no recent parent meetings was $12.4 \%$.

Education levels in the community affect absence through a variety of channels, including the greater ability of literate parents to judge the quality of students' education. The mean absence rate of teachers in schools where there were low parental literacy rate was $16.4 \%$ and the mean 
absence rate of teachers in schools where there were high parental literacy rate was $7.7 \%$.

Education levels in the community affect absence through a variety of channels, including the greater ability of literate parents to judge the quality of students' education. The mean absence rate of teachers in schools where there were low parental literacy rate was $16.4 \%$ and the mean absence rate of teachers in schools where there were high parental literacy rate was $7.7 \%$.

Another possible source of performance pressure on school headteachers and teachers is competition from private schools in the local area. If students have a credible exit option, or if the private school serves to benchmark performance, the Government schools may feel pressured to improve. The survey results show that the private competition is associated with sharply lower absence rates. The average teacher absence rate is only $7.7 \%$ in places where private school exist nearby, where as the average teacher absence rate is $16.7 \%$ in places where no private school exist nearby. This finding is in consistent with the research results found by Hoxby (Hoxby 1994, p.17).

Compared with Tuesday, Wednesday and Thursday the coefficients for the Monday and Friday dummies are large and often statistically significant, suggesting that teachers are often absent on what could be long weekends. This finding is similar to the results found in the studies of Unicomb, Alley, and Barak (Unicomb et al. 1992, p. 36).

In table 3, the means and standard deviations and ranges for the dependent variables are shown.

Table 3 Descriptive Statistics

\begin{tabular}{|l|r|r|r|r|}
\hline \multicolumn{1}{|c|}{ Variables } & \multirow{2}{*}{ Mean } & \multirow{2}{*}{ SD } & \multicolumn{2}{c|}{ Range } \\
\cline { 4 - 5 } & & & Minimum & Maximum \\
\hline Job Satisfaction & 2.49 & 0.55 & 0.00 & 3.00 \\
Job Involvement & 4.39 & 1.19 & 1.66 & 9.00 \\
Role Conflict & 4.04 & 1.62 & 1.00 & 8.00 \\
Organisation Tenure & 12.98 & 7.29 & 0.00 & 29.00 \\
Employee Age & 39.32 & 8.24 & 26.00 & 55.00 \\
Number of Dependents & 1.07 & 1.15 & 0.00 & 6.00 \\
Total days absent & 4.67 & 6.65 & 0.00 & 54.00 \\
Absence frequency & 2.54 & 1.78 & 0.00 & 8.00 \\
\hline
\end{tabular}


Pearson product-moment correlation coefficients for the variables are used in this study. A positive significant correlation of $0.579(p<.001)$ was found to exist between absence frequency and total days of absence. Positive correlations were found for absence frequency and job involvement $(r=0.159, p<.01)$ and general job satisfaction $(r=.117, p .<05)$. The general measure of job satisfaction was positively correlated with job involvement $(r=.133, p<.05)$. The number of dependents a teacher had was positively correlated with job involvement $(r=.131, p .<.05)$ and role conflict $(r=236, p<.001)$. Finally role conflict was negatively correlated with organisation tenure $(r=-.187, p .<01)$ and age $(r=$ $.281, p<.001)$. Research unanimously supports the contention that school climate affects job satisfaction on the part of staff personnel. When job satisfaction is positive, staff personnel are motivated toward serving the organization and goal achievement. Such an attitude leads to improved attendance. The result of this finding is similar to the results found by Patrick (Patrick 1995, p. 32), Taylor and Tashakori (Taylor \& Tashakori1994, p. 17), Hoy and Miskel (Hoy \& Miskel 1996, p. 72).

\section{Discussion}

The variables like gender, age, tenure, distance from home to work, number of dependents, the role conflict, job satisfaction in general, central life interest and job involvement are related to attendance behaviour of the teachers. Some absenteeism due to these variables is not only likely but expected over time. However school administrators may have some tools at their disposal to reduce absenteeism that is related to variables like distance from home to work and gender. School administrators could provide staff quarters for the teachers near the school campus or by arranging school bus to pick up the teachers from their residence to the school on time and thereby reduce absenteeism that is related to travel. Traditionally, absenteeism associated with women teachers has been attributed to child care responsibilities. School administrators could play an important role in reducing this type of absenteeism by providing facilities such as child care referral services and by emphasizing the importance of the teachers job, women teachers could be encouraged to share more of the child care responsibility with their spouses.

Implications also arose from the findings that teachers who are generally more satisfied with their jobs have less absenteeism. Thus it becomes important to consider factors that encourage higher levels of satisfaction for 
teachers. Improving the feacher-administration relationship, reducing excessive clerical work required of teachers, better handling of student's behavioural problems and consistency in dealing with student discipline problems are some of the factors that encourage higher levels of satisfaction for teachers.

If social pressure on teachers and intrinsic orientation toward service to the community are important, then teachers who come from the area near the school might have lower absence rates (Jacobson et al. 1993, p. 12). In our data, this effect comes through strongly. A teacher who is born in the district where the school is located has a much lower absence rate and the effect is generally highly significant.

Another plausible measure of ties to the community is the teacher's tenure at the school. Teachers with longer tenure feel a greater connection to the community, increasing their non-pecuniary motivation. Increasing the tenure of the services of teachers in a particular school will enable them to have closer ties with the communities and that will increase their responsibilities towards the communities and consequently the absence rate of teachers will also decline.

Friendly relations and leadership style of the school headmasters were found to be associated with the rate of teacher absences. Teachers who had supportive principals were less likely to report stress-related illnesses than those with unsupportive principals. The findings suggest that Organizational support increases an employee's efforts to meet the organization's goals through greater attendance.

Research findings unanimously support the argument that school climate affects job satisfaction on the part of school teachers. It seems a truism that a school where teachers feel happy and appreciated will be less likely to have high levels of staff absenteeism than one where the reverse is the case. When job satisfaction is positive, staff personnel are motivated toward serving the organization and goal achievement (Eisenberg et al. 1986, p. 502). Such an attitude leads to improved attendance.

A set of beliefs and practices among a school's staff concerning what frequency and duration of absence is individually and organizationally acceptable, or what they define as the 'absence culture', can be of critical importance. The social context of the school may have more bearing on its absenteeism level than the sum of individuals' contributions to that level. 
Workplace norms which tolerate high levels of absence are likely to maintain those levels irrespective of who is appointed to the staff. So adoptions of prompt measures to change the 'absence culture' of the schools are important to reduce the absence rate of teachers from the Government schools.

Healthy teachers are less likely to fall ill, and a wellness program can encourage good health. Teacher absenteeism can be reduced by offering the teachers' medical screening, fitness assessment, goal setting, exercise and nutrition prescriptions, health education, exercise classes, motivation, and feedback.

\section{Limitations}

Some limitations on the generalizability of this study's results are listed below. Inferences from this study must take these limitations into account:

1. The findings of the study are subject to the limitations associated with survey and interview data collection;

2. The study is further limited in that it used self-report measures of absence, which is highly subjective.

3. Data obtained from a uncontrolled laboratory experimental situation, as real world situations do not necessarily conform to controlled clinical laboratory settings;

4. Demographics of the schools.

5. Another limitation to the study was that the impact, by school, was not examined in depth.

\section{Conclusion}

Teacher absenteeism is an important issue that deserves school authorities' utmost attention, as it certainly has a negative pedagogical impact. Aware of the direct and indirect impacts associated with absenteeism, the school management must find out the specific factors that are responsible for teacher absenteeism and take appropriate measures to curb this challenging problem. 
The study focused on the relationship between personal characteristics, school characteristics, community characteristics and absence of teachers. Significant correlations were found and it is important for school management to understand these dynamics in order to control absenteeism in the workplace. Schools need to have stringent policies in place to control absenteeism, and a culture of attendance needs to be cultivated amongst teachers. School headmasters should introduce support measures that serve to improve work and working conditions for teachers. Provisions for the airing of grievances, student discipline, evaluation of performance, and feedback on work performance are examples of such support measures. Employee assistance programs should be established in the schools that provide for personal counseling for teachers who have excessive absences.

\section{References}

Boudreau, C. A., Christian, W. P. \& Thibadeau, S. F. (1993). Reducing absenteeism in a human service setting: a low cost alternative, Journal of Organizational Behavior Management, 13, pp. 37-50.

Breaugh, J.A. (1981). Predicting absenteeism from prior absenteeism and work attitudes, Journal of Applied Psychology, 66, pp. 555-560.

Bridges, E. M. (1980). Job satisfaction and teacher absenteeism, Educational Administration Quarterly, 16, pp. 41-56.

Dworkin, A. G., Haney, C. A., Dwokin, R. J. \& Telschov, R. L. (1990). Stress and illness behavior among urban public school teachers, Educational Administration Quarterly, 26, pp. 60-72.

Eisenberg, R., Huntington, R., Hutchison, S. \& Sowa, D. (1986). Perceived organizational support. Journal of Applied Psychology, 71(3), pp. 500-507.

Government of Kerala, Economic Review 2008, State Planning Board, Thiruvananthapuram, February 2009, pp. 259-262.

Hoxby, C. (1994). Do Private Schools Provide Competition For Public Schools? National Bureau of Economic Research Working Paper: 34.

Hoy, W.K, \& Miskel, C.G. (1996). Educational administration: Theory research and practice (5th ed.) New York: McGraw-Hill, Inc., p. 72.

Imants, J. \& Van Zoelen, A. (1995). Teachers' sickness absence in primary schools, school climate and teachers' sense of efficacy, School Organization, 15, pp. 77-87.

Jacobson, S. L. (1989). The effects of pay incentives on employee absenteeism, Journal of Human Resources, 24, pp. 280-286. 
Jacobson, S. (1990). Attendance incentives and teacher absenteeism. Planning and Changing, 21 (2), pp. 78-93.

Jacobson, S. L., Gibson, R. O. \& Ramming, T. (1993). Toward a reconception of absence in the school workplace: teacher absenteeism as invention and social exchange, paper presented to the American Education Finance Association, ERIC Document 357502.

Keller, R. (1983). Predicting absenteeism from prior absenteeism, attitudinal factors and non attitudinal factors, Journal of Applied Psychology, 68, pp. 536-540.

Norton, M. S. (1998). Teacher absenteeism: a growing dilemma, Contemporary Education, 69, pp. 95-99.

Patrick, J.E. (1995). Correlation between administrative styles and school climate. EDRS, Accession number ED 387853.

Pitkoff, E. (1993). Teacher absenteeism: What administrators can do? NASSP Bulletin. 77 (551), pp. 39-45.

Porwoll, P. (1980). Employee absenteeism: A summary of research. Arlington, VA: Educational Research Service.

Scott, D. \& Wimbush, J. (1991). Teacher absenteeism in secondary education, Educational Administration Quarterly, 27, pp. 506-529.

Scott, K. \& McClellen, E. (1990). Gender differences in absenteeism, Public Personnel Management, 19(2), pp. 229-253.

Scott, K., Markham, S., \& Robers, R. (1985). Rewarding good attendance: A comparative study of positive ways to reduce absenteeism. Personnel Administrator, 30, p. 8.

Steers, R. M., \& Rhodes, S. R. (1978). Major influences on employees' attendance: a process model. Journal of Applied Psychology, 63(4), pp. 391-407.

Taylor, D.L., \& Tashakori, A. (1994). Predicting teachers' sense of efficacy and job satisfaction using school climate and participatory decision making. Paper presented at the annual meeting of the Southwest Educational Research Association, San Antonio, Texas.

Unicomb, R., Alley, J., \& Barak, L. (1992). Teacher absenteeism: A study of short term teacher absenteeism in nine Nova Scotia schools which shows that teachers are absent significantly less than workers in other professions. Education Canada, 32 (2), pp. 33-37. 